\title{
Vitamin and trace element concentrations in infants and children with chronic kidney disease
}

\author{
Triona Joyce $^{1} \cdot$ Pernille Rasmussen $^{2} \cdot$ Nabil Melhem ${ }^{2} \cdot$ Joanna Clothier $^{2} \cdot$ Caroline Booth $^{2} \cdot$ Manish D Sinha $^{2,3}$
}

Received: 18 September 2019 / Revised: 3 March 2020 / Accepted: 6 March 2020 / Published online: 14 April 2020

(C) The Author(s) 2020

\begin{abstract}
Background There are limited data regarding vitamin and trace element blood concentrations and supplementation needs in children with non-dialysis stages 3-5 of chronic kidney disease (CKD).

Methods Retrospective cross-sectional review for nutritional blood concentrations measured over a recent 2-year period. In our CKD clinics, nutritional bloods including copper, zinc, selenium and vitamin $\mathrm{A}$, vitamin $\mathrm{E}$, active vitamin $\mathrm{B}_{12}$ and folate are monitored annually. Vitamin D status is monitored every 6-12 months.

Results We reviewed 112 children (70 boys) with median (IQ1, IQ3) age $8.97(4.24,13.80)$ years. Estimated median (IQ1, IQ3) GFR $\left(\mathrm{mL} / \mathrm{min} / 1.73 \mathrm{~m}^{2}\right)$ was $28(21,37)$. Vitamin A, active vitamin $\mathrm{B}_{12}$ and vitamin E concentrations were within normal range in $19 \%, 23 \%$ and $67 \%$ respectively, with all others being above normal range. Vitamin D blood concentrations were within desired range for $85 \%$ ( $15 \%$ had low levels) and folate blood concentrations were within normal range in $92 \%$, with the remainder above or below target. For trace elements, $60 \%, 85 \%$ and $87 \%$ achieved normal ranges for zinc, selenium and copper respectively. Deficiencies were seen for zinc (35\%), copper (7\%), folate (3\%) and selenium (1\%), whilst 5\%, $6 \%$ and $14 \%$ had zinc, copper and selenium levels above normal ranges.

Conclusions Several vitamin and trace element blood concentrations were outside normal reference ranges. Monitoring vitamin D and zinc blood concentrations is indicated due to the percentages with low levels in this group. Targeted vitamin and trace element supplementation should be considered where indicated rather than commencing multivitamin and/or mineral supplementation.
\end{abstract}

Keywords Chronic kidney disease $\cdot$ Vitamins $\cdot$ Trace elements $\cdot$ Blood monitoring

\section{Introduction}

Children with chronic kidney disease (CKD) may be at risk of micronutrient deficiencies due to multiple factors, which may

Electronic supplementary material The online version of this article (https://doi.org/10.1007/s00467-020-04536-0) contains supplementary material, which is available to authorized users.

Manish D Sinha

manish.1.sinha@kcl.ac.uk

1 Department of Nutrition and Dietetics, Evelina London Children's Hospital, Guys \& St Thomas' NHS Foundation Trust, Westminster Bridge Road, London SE1 7EH, UK

2 Department of Paediatric Nephrology, Evelina London Children's Hospital, Guys \& St Thomas' NHS Foundation Trust, 3rd Floor Beckett House, Westminster Bridge Road, London SE1 7EH, UK

3 Kings College London, London, UK include inadequate intake as a result of dietary restrictions, anorexia or interference with absorption, metabolism and excretion [1]. The provision of adequate quantities of micronutrients is important due to their role in paediatric growth and development [1].

$\mathrm{K} / \mathrm{DOQI}$ guidelines have recommended that the provision of the dietary reference intake (DRI) for several micronutrients, including copper, zinc and vitamins $\mathrm{A}, \mathrm{E}$ and $\mathrm{C}$ and folic acid should be considered in children with CKD stages 2 to 5 [1]. In the UK, recommended nutrient intakes (RNI) are estimates of requirements for the healthy population and may not meet the needs of children with CKD [2]. With regard to vitamin and trace element supplementation, K/DOQI guidelines suggest supplementation if dietary intake does not meet $100 \%$ of the DRI or where there is clinical evidence of a deficiency [1]. However, it has been acknowledged that micronutrient deficiencies progress slowly in most cases with clinical manifestations indistinguishable from those of CKD [3]. With the exception of vitamin D (25 
hydroxy vitamin $\mathrm{D}$ ), there are limited data regarding micronutrient and trace element status, requirements and supplementation needs in infants and children with CKD.

In the CKD clinics at the Evelina London Children's Hospital, nutritional bloods including copper, zinc, selenium and vitamin $\mathrm{A}$, vitamin $\mathrm{E}$, active vitamin $\mathrm{B}_{12}$ (holotranscobalamin) and folate are monitored annually and vitamin D (25 hydroxy vitamin D) status every 6-12 months. Infants and children are not routinely supplemented with micronutrient supplements. Our objective in this study was to evaluate the blood concentrations of trace elements and vitamins in children with non-dialysis stages 3-5 of CKD, including those on nutritional supplementation.

\section{Methods}

We performed a retrospective cross-sectional review of nutritional blood concentrations in children attending the nondialysis CKD clinics at our centre over a recent 2-year period. Additional data collected included patient demographics (age, gender, ethnicity), primary renal diagnosis and micronutrient supplementation. We categorized patients into sub-groups by their method of diet intake as (i) diet alone: those who were taking diet without any nutritional supplementation; (ii) enteral tube feed: those receiving some or all of their nutrition via nasogastric or gastrostomy tubes; and (iii) oral nutritional supplements (ONS) (also known as sip feeds): those taking nutritional supplements orally. Additionally, children on any micronutrient supplementation (vitamin and/or trace elements) were identified. The micronutrient supplements included ABIDEC $\AA$ multivitamin drops, Dalivit ${ }^{\circledR}$ drops, FruitiVits $\AA$, Floradix ${ }^{\circledR}$ liquid iron and vitamin formula, Forceval ${ }^{\circledR}$ capsules, Millhouse Jelly Bear® multivitamins, Wellteen ${ }^{\circledR}$ Her/ Him, Wellkid® multivitamin liquid and Wellbaby ${ }^{\circledR}$ multivitamin liquid (please see online Supplementary Table for specific content).

All measurements were obtained using electronic patient records. Information on the vitamin and trace element content of the enteral tube feeds was obtained using the software program Electronic Dietetic Manager (EDM 2000 ${ }^{\mathrm{TM}}$, MicroMan2000 Ltd, PO box 3721, Newport Pagnell, UK).

Data are displayed as number (percentage), median and interquartile range (IQR) where appropriate for all children. Values were reported as 'above', 'within range' or 'normal', and 'below' for all reported micronutrients. Micronutrient intakes were compared with the RNI. The Kruskal-Wallis test was used to compare median ages and micronutrient concentrations between the different CKD stages. Chi-square test and ANOVA were used to compare groups. The Mann-Whitney test was used to compare non-parametric data. Analysis was performed using SPSS version 25 (SPSS Inc., Chicago, IL) and $p<0.05$ was taken as significant.

\section{Results}

A total of 112 children were included during the study period with a median (IQ1, IQ3) age of 8.97 (4.24, 13.80) years. Estimated median (IQ1, IQ3) GFR ( $\mathrm{mL} / \mathrm{min} / 1.73 \mathrm{~m}^{2}$ ) was $28(21,37)$. Patient characteristics for the total group and by CKD stages 3 to 5 are shown in Table 1. Eighty-eight of 112 $(78.6 \%)$ children were on diet alone, 20 (17.8\%) on enteral tube feeds and four (3.6\%) on ONS. Overall, 19 of $112(17 \%)$ children were receiving a micronutrient supplement, including 17 of $88(19.3 \%)$ who were on diet alone and 2 of the 20 (10\%) children receiving enteral tube feeds. There were no patients on micronutrient supplements in the ONS group.

Ninety-eight children had nutritional blood results for all eight vitamins and trace elements. Of these, the majority $(n=93)$ had $\geq 1$ vitamin or trace element abnormality outside of the normal reference range and $52(53 \%)$ had $\geq 1$ of both vitamin and trace element abnormalities. Table 2 shows the median (IQI, IQ3) blood concentrations of vitamin and trace elements in the total group and by CKD stages 3-5. The percentages of vitamin and trace element concentrations below, within and above their reference ranges are shown in Fig. 1. The majority of children had adequate vitamin $\mathrm{E}$ concentrations, with significantly increasing concentrations with worsening stages of CKD $(p=0.019)$. Table 3 shows patient characteristics and vitamin and trace element concentrations in those on diet alone versus those receiving nutritional supplementation (patients in the enteral tube feed and ONS sub-groups). The laboratory reference ranges for vitamin and trace elements at our unit are shown in Tables 4 and 5.

\section{Diet alone group}

Patient characteristics of the 88 children in this group are shown in Table 3. Vitamin D and vitamin E concentrations were lower in those on diet alone when compared with those receiving nutritional supplementation (vitamin $\mathrm{D}[66(54,87)$ versus $84(77,102) \mathrm{nmol} / \mathrm{L}, p=0.001]$ and vitamin $\mathrm{E}$ [28.9 $(25.1,33.9)$ versus $34.1(28.1,39.5) \mu \mathrm{mol} / \mathrm{L}, p=0.008]$, respectively).

\section{Vitamins}

Active vitamin $\mathrm{B}_{12}$, vitamin $\mathrm{A}$ and vitamin $\mathrm{E}$ blood concentrations were within range in $29 \%(n=24 / 84), 21 \%(n=17 /$ $81)$ and $74 \%(n=60 / 81)$ respectively, with all others above the normal range. Ten of the children with raised active vitamin $B_{12}$ blood concentrations were receiving micronutrient supplements which contained vitamin $\mathrm{B}_{12}$ providing between 100 and $1000 \%$ respectively of the reference nutrient intake (RNI) for vitamin $\mathrm{B}_{12}$. Four children had high folate blood concentrations and two of these were receiving micronutrient 
Table 1 Patient characteristics for the total study group and by chronic kidney disease stages $3-5$

\begin{tabular}{|c|c|c|c|c|c|}
\hline & Total $(n=112)$ & Stage $3(n=50)$ & Stage $4(n=48)$ & Stage $5(n=14)$ & \\
\hline Age in years, median (IQ1, IQ3) & $8.97(4.24,13.80)$ & $9.08(4.62,12.90)$ & $9.35(4.42,14.66)$ & $6.12(0.94,9.97)$ & $p=0.139$ \\
\hline \multicolumn{6}{|l|}{ Gender, $n(\%)$} \\
\hline Girls & $42(37 \%)$ & $18(36 \%)$ & $20(42 \%)$ & $4(29 \%)$ & \multirow[t]{2}{*}{$p=0.644$} \\
\hline Boys & $70(63 \%)$ & $32(64 \%)$ & $28(58 \%)$ & $10(71 \%)$ & \\
\hline \multicolumn{6}{|l|}{ Ethnicity, $n(\%)$} \\
\hline White & $68(61 \%)$ & $34(68 \%)$ & $25(52 \%)$ & $9(64.3 \%)$ & \multirow[t]{5}{*}{$p=0.33$} \\
\hline Black & $14(12 \%)$ & $4(8 \%)$ & $9(19 \%)$ & $1(7.1 \%)$ & \\
\hline Asian & $14(12 \%)$ & $4(8 \%)$ & $8(17 \%)$ & $2(14.3 \%)$ & \\
\hline Mixed & $13(12 \%)$ & $5(10 \%)$ & $6(12 \%)$ & $2(14.3 \%)$ & \\
\hline Other & $3(3 \%)$ & $3(6 \%)$ & - & - & \\
\hline \multicolumn{5}{|l|}{ Causes of CKD, $n(\%)$} & \multirow[t]{9}{*}{$p=0.327$} \\
\hline Glomerular disease & $3(3 \%)$ & $2(4 \%)$ & $1(2 \%)$ & - & \\
\hline Tubulo-interstitial disease & $5(4 \%)$ & - & $4(8 \%)$ & $1(7.1 \%)$ & \\
\hline Metabolic disease & $7(6 \%)$ & $6(12 \%)$ & $1(2 \%)$ & - & \\
\hline Renovascular disease & $12(11 \%)$ & $5(10 \%)$ & $7(15 \%)$ & - & \\
\hline Obstructive uropathy & $27(24 \%)$ & $11(22 \%)$ & $13(27 \%)$ & $3(21.4 \%)$ & \\
\hline Renal dysplasia \pm reflux nephropathy & $55(49 \%)$ & $25(50 \%)$ & $20(42 \%)$ & $10(71.4 \%)$ & \\
\hline Polycystic & $1(1 \%)$ & - & $1(2 \%)$ & - & \\
\hline Uncertain & $2(2 \%)$ & $1(2 \%)$ & $1(2 \%)$ & - & \\
\hline Estimated GFR (mL/min/1.73 m²), median (IQ1, IQ3) & $28(21,37)$ & $38(35,44)$ & $24(19,27)$ & $12(11,13)$ & $p<0.01$ \\
\hline Micronutrient supplement, $n(\%)$ & $19(17 \%)$ & $9(18 \%)$ & $7(15 \%)$ & $3(21 \%)$ & $p=0.807$ \\
\hline Enteral feed, $n(\%)$ & $20(18 \%)$ & $5(10 \%)$ & $13(27 \%)$ & $2(14 \%)$ & $p=0.082$ \\
\hline
\end{tabular}

IQ1 interquartile 1, IQ3 interquartile 3, CKD chronic kidney disease

supplements which contained folate providing $67 \%$ (also receiving a folic acid supplement) and $160 \%$ of the RNI for folate. One other child was receiving a folic acid supplement. Thirteen children with high vitamin A blood concentrations were receiving micronutrient supplements which contained vitamin A providing $33-375 \%$ of the RNI $(\leq 50 \%$ of the RNI in 6 children). Vitamin D blood concentrations were deficient in four and insufficient in 14 patients. Seven patients received cholecalciferol at some point during the study. One further patient received a vitamin D-containing supplement but no cholecalciferol.

\section{Trace elements}

Copper blood concentrations were below the reference range in five children, three of which were only marginally below the reference range. Two of the children with low copper blood concentrations ( 5 and $8 \mu \mathrm{mol} / \mathrm{L}$ ) were receiving a micronutrient supplement containing copper providing $21 \%$ and $100 \%$ of the RNI for copper respectively. Five children had blood copper concentrations above the normal reference range, one of whom was receiving supplement providing $25 \%$ of the RNI for copper. Zinc blood concentrations were below the normal reference range in $34 \%(n=$
28/82) of children. Six children with zinc concentrations below the normal range and one with high zinc blood concentrations $(45.5 \mu \mathrm{mol} / \mathrm{L})$ were receiving micronutrient supplements containing zinc providing 50-158\% (50$60 \%$ of the RNI in 3 patients) and $62 \%$ of the RNI for zinc respectively. Five other children were receiving zinc supplements to treat low zinc blood concentrations. Selenium blood concentrations were above the normal range in eight (10\%) patients, of whom one child was receiving a micronutrient supplement which contained selenium providing $137 \%$ of the RNI. Only one child had a low selenium blood concentration $(0.32 \mu \mathrm{mol} / \mathrm{L})$ with the supplement providing $92 \%$ of the RNI.

\section{Enteral tube feed group}

Twenty children were receiving enteral tube feeds, including 11 boys, median age $7.32(4.24,9.61)$ years, of whom 19 had minimal or no food intake. None of the children was receiving an enteral tube feed that was entirely a paediatric renalspecific feed. Active vitamin $\mathrm{B}_{12}$, vitamin $\mathrm{A}$, vitamin $\mathrm{E}$, selenium and folate blood concentrations were within range in $5 \%, 6 \%, 41 \%, 72 \%$ and $95 \%$ respectively, with all others above the normal range. 
Table 2 Median (IQ1, IQ3) blood concentrations of vitamins and trace elements in the total group and by chronic kidney disease stages 3-5

\begin{tabular}{|c|c|c|c|c|c|c|c|c|c|}
\hline & \multicolumn{2}{|c|}{ Total $(n=112)$} & \multicolumn{2}{|c|}{ Stage $3(n=50)$} & \multicolumn{2}{|c|}{ Stage $4(n=48)$} & \multicolumn{3}{|c|}{ Stage $5(n=14)$} \\
\hline & $n$ & Median (IQ1, IQ3) & $n$ & Median (IQ1, IQ3) & $n$ & Median (IQ1, IQ3) & $n$ & Median (IQ1, IQ3) & \\
\hline \multicolumn{10}{|l|}{ Vitamins } \\
\hline Vitamin A $(\mu \mathrm{mol} / \mathrm{L})$ & 101 & $2.52(2.06,3.24)$ & 43 & $2.45(1.97,2.78)$ & 44 & $2.57(2.25,3.41)$ & 14 & $2.70(2.17,3.94)$ & $p=0.122$ \\
\hline Vitamin D (nmol/L) & 112 & $73(57,89)$ & 50 & $70(55,92)$ & 48 & $75(55,88)$ & 14 & $77(61,106)$ & $p=0.652$ \\
\hline Vitamin $E(\mu \mathrm{mol} / \mathrm{L})$ & 101 & $29.8(25.3,34.7)$ & 43 & $27.4(25.2,30.4)$ & 44 & $31.9(26.5,37.1)$ & 14 & $33.3(28.5,39.1)$ & $\mathrm{p}=0.019$ \\
\hline \multicolumn{10}{|l|}{ Trace elements } \\
\hline Copper $(\mu \mathrm{mol} / \mathrm{L})$ & 104 & $17(13,20)$ & 45 & $16(14,19)$ & 45 & $17(13,21)$ & 14 & $17(15,20)$ & $p=0.867$ \\
\hline $\operatorname{Zinc}(\mu \mathrm{mol} / \mathrm{L})$ & 103 & $11.6(10.4,12.8)$ & 44 & $11.4(10.4,12.8)$ & 45 & $11.9(9.8,13.3)$ & 14 & $12.2(11.0,12.8)$ & $p=0.917$ \\
\hline Selenium $(\mu \mathrm{mol} / \mathrm{L})$ & 104 & $1.17(1.02,1.33)$ & 45 & $1.17(1.04,1.28)$ & 45 & $1.14(1.01,1.33)$ & 14 & $1.21(0.95,1.43)$ & $p=0.769$ \\
\hline
\end{tabular}

IQ1 interquartile 1, IQ3 interquartile 3

As vitamin $B_{12}$ and folate results above range were reported as $>128 \mathrm{pmol} / \mathrm{L}$ and $>20 \mu \mathrm{g} / \mathrm{L}$ respectively values for these are not displayed

\section{Vitamins}

All of the children who were receiving enteral tube feeds had high active vitamin $\mathrm{B}_{12}$ blood concentrations. The enteral tube feed for only one of these was providing less than the RNI for vitamin $\mathrm{B}_{12}(90 \%)$. In all others, the enteral tube feeds provided between $100 \%$ and almost 5 times the RNI for vitamin $B_{12}$. Two other children were receiving a multivitamin that contained vitamin $\mathrm{B}_{12}$ which increased their vitamin $\mathrm{B}_{12}$ intake from approximately $190 \%$ and $370 \%$ of the RNI to greater than 4 and 5 times the RNI respectively. The majority of children had raised vitamin $\mathrm{A}$ blood concentrations $(n=16 / 17)$ with feeds providing 45 to $205 \%$ of the RNI $(<100 \%$ of the RNI in 8 children). Two children were receiving a micronutrient supplement that contained vitamin A which provided $40 \%$ and $33 \%$ of the RNI for vitamin A, increasing their total vitamin intake to $114 \%$ and $238 \%$ respectively. All of the children receiving enteral feeds had normal vitamin D blood concentrations.

\section{Trace elements}

Zinc blood concentrations were below the normal range in $44 \%(n=8 / 18)$ of children, one of whom (zinc concentration $5.5 \mu \mathrm{mol} / \mathrm{L}$ ) was also receiving a micronutrient supplement which contained zinc. The enteral feed for the latter was providing $9 \mathrm{mg}$ zinc daily (RNI $7 \mathrm{mg}$ /day). Zinc blood concentrations were marginally below the normal range (10 to $10.8 \mu \mathrm{mol} / \mathrm{L}$ ) in three patients with enteral feeds providing $46 \%$ (supplementary feed providing $\sim 14 \%$ of their calorie needs), $100 \%$ and $107 \%$ of the RNI for zinc. The enteral feeds for the remaining patients provided between 71 and $167 \%$ of the RNI for zinc. One child had a marginally low copper blood concentration $(11 \mu \mathrm{mol} / \mathrm{L})$ with enteral feeds providing $135 \%$ of the RNI for copper.

\section{ONS group}

In the four children in this group, zinc, folate, active vitamin $\mathrm{B}_{12}$ and vitamin $\mathrm{D}$ blood concentrations were all within range.
Fig. 1 Percentage of mean vitamin and trace element concentrations that were below, within and above their reference ranges

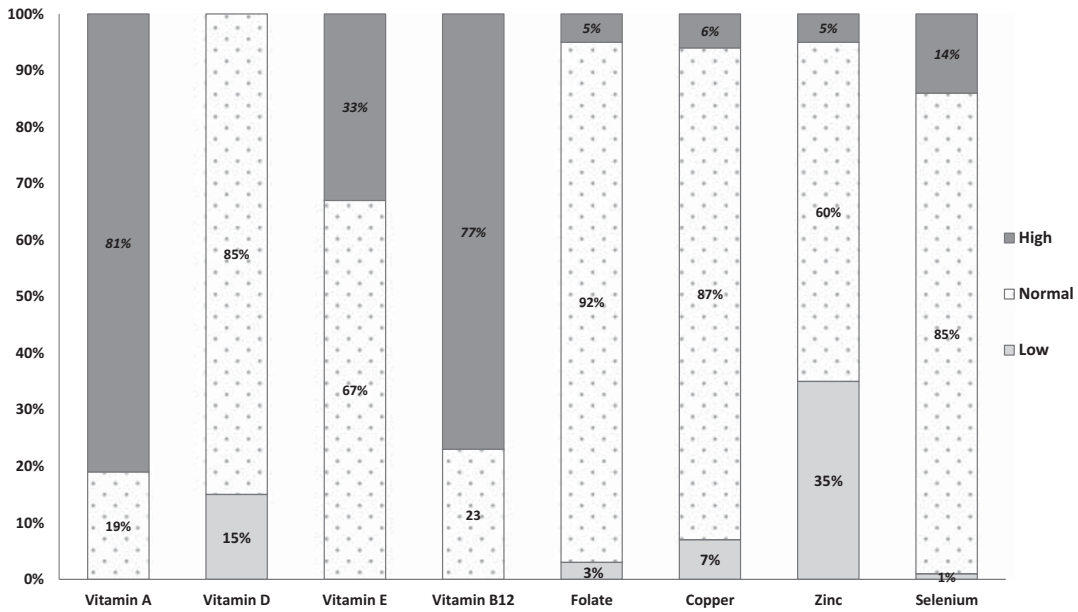


Table 3 Patient characteristics and vitamin and trace element concentrations in the diet alone and enteral tube feed and oral nutritional supplement (ONS) groups

\begin{tabular}{|c|c|c|c|}
\hline & Diet group $(n=88)$ & Enteral tube feed and ONS groups $(n=24)$ & \\
\hline Age in years, median (IQ1, IQ3) & $9.44(4.20,14.04)$ & $7.60(4.24,11.73)$ & $p=0.194$ \\
\hline \multicolumn{4}{|l|}{ Gender, $n(\%)$} \\
\hline Girls & $30(34 \%)$ & $12(50 \%)$ & \multirow[t]{2}{*}{$p=0.15$} \\
\hline Boys & $58(66 \%)$ & $12(50 \%)$ & \\
\hline \multicolumn{4}{|l|}{ Ethnicity, $n(\%)$} \\
\hline White & $55(63 \%)$ & $13(54.1 \%)$ & \multirow[t]{5}{*}{$p=0.712$} \\
\hline Black & $11(13 \%)$ & $3(12.5 \%)$ & \\
\hline Asian & $10(11 \%)$ & $4(16.7 \%)$ & \\
\hline Mixed & $9(10 \%)$ & $4(16.7 \%)$ & \\
\hline Other & $3(3 \%)$ & - & \\
\hline \multicolumn{3}{|l|}{ Causes of CKD, $n(\%)$} & \multirow[t]{9}{*}{$p=0.609$} \\
\hline Glomerular disease & $3(3 \%)$ & - & \\
\hline Tubulo-interstitial disease & $4(5 \%)$ & $1(4 \%)$ & \\
\hline Metabolic disease & $5(6 \%)$ & $2(8 \%)$ & \\
\hline Renovascular disease & $9(10 \%)$ & $3(13 \%)$ & \\
\hline Obstructive uropathy & $21(24 \%)$ & $6(25 \%)$ & \\
\hline Renal dysplasia \pm reflux nephropathy & $44(50 \%)$ & $11(46 \%)$ & \\
\hline Polycystic & - & $1(4 \%)$ & \\
\hline Uncertain & $2(2 \%)$ & - & \\
\hline Estimated GFR (mL/min/1.73 m²), median (IQ1, IQ3) & $29(22,38)$ & $25(17,31)$ & $p=0.119$ \\
\hline \multicolumn{4}{|l|}{ Vitamins } \\
\hline Vitamin A ( $\mu \mathrm{mol} / \mathrm{L})$, median (IQ1, IQ3) $(n)$ & $2.52(2.04,3.24)(81)$ & $2.53(2.28,3.22)(20)$ & $p=0.779$ \\
\hline Vitamin D (nmol/L), median (IQ1, IQ3) (n) & $66(54,87)(88)$ & $84(77,102)(24)$ & $p=0.001$ \\
\hline Vitamin E $(\mu \mathrm{mol} / \mathrm{L})$, median (IQ1, IQ3) $(n)$ & $28.9(25.1,33.9)(81)$ & $34.1(28.1,39.5)(20)$ & $p=0.008$ \\
\hline \multicolumn{4}{|l|}{ Trace elements } \\
\hline Copper $(\mu \mathrm{mol} / \mathrm{L})$, median (IQ1, IQ3) $(n)$ & $16(13,19)(83)$ & $19(16,23)(21)$ & $p=0.017$ \\
\hline Zinc ( $\mu$ mol/L), median (IQ1, IQ3) $(n)$ & $11.5(10.4,12.6)(82)$ & $12.8(10.25,14.55)(21)$ & $p=0.064$ \\
\hline Selenium ( $\mu \mathrm{mol} / \mathrm{L})$, median (IQ1, IQ3) $(n)$ & $1.14(1.02,1.29)(83)$ & $1.26(1.00,1.52)(21)$ & $p=0.128$ \\
\hline
\end{tabular}

IQ1 interquartile $1, I Q 3$ interquartile 3

Vitamin A, vitamin E and selenium blood concentrations were within the normal range for $33 \%$ of patients with the remainder above the normal range. No child was receiving

Table 4 Laboratory reference ranges for folate, vitamin D, vitamin $\mathrm{B}_{12}$, copper, zinc and selenium

\begin{tabular}{ll}
\hline Variable & Normal range \\
\hline Folate & $3.1-20.5 \mu \mathrm{g} / \mathrm{L}$ \\
Vitamin D & $<30 \mathrm{nmol} / \mathrm{L}$ (deficiency), 30-50 nmol/L (insufficiency) \\
Vitamin $\mathrm{B}_{12}$ & $25-108 \mathrm{pmol} / \mathrm{L}$ \\
Selenium & $0.44-1.43 \mu \mathrm{mol} / \mathrm{L}$ \\
Zinc & $11-19 \mu \mathrm{mol} / \mathrm{L}$ \\
Copper & $1.4-7.2 \mu \mathrm{mol} / \mathrm{L}(0-4$ months $)$ \\
& $3.9-17.3 \mu \mathrm{mol} / \mathrm{L}$ (4-6 months) \\
& $7.9-20.5 \mu \mathrm{mol} / \mathrm{L}$ (7-12 months) \\
& $12-25 \mu \mathrm{mol} / \mathrm{L}(>1$ year) \\
\hline
\end{tabular}

cholecalciferol. Only one child had a marginally low copper blood concentration $(11 \mu \mathrm{mol} / \mathrm{L})$ with their ONS providing $73 \%$ of the RNI for copper.

Table 5 Laboratory reference ranges for vitamin A and vitamin $\mathrm{E}$

\begin{tabular}{lll}
\hline Age (years) & Vitamin A $(\mu \mathrm{mol} / \mathrm{L})$ & Vitamin E $(\mu \mathrm{mol} / \mathrm{L})$ \\
\hline $0-2$ & $0.49-1.43$ & $0.0-25.0$ \\
$3-5$ & $0.56-1.47$ & $7.0-30.1$ \\
$6-8$ & $0.66-2.00$ & $10.0-34.8$ \\
$9-11$ & $0.77-2.06$ & $13.9-32.5$ \\
$12-13$ & $0.84-2.20$ & $10.9-34.8$ \\
$14-15$ & $0.94-2.65$ & $13.9-32.5$ \\
$16+$ & $1.40-3.84$ & $11.6-41.8$ \\
\hline
\end{tabular}




\section{Discussion}

We report the largest study of vitamin and trace element concentrations in non-dialysis children with residual renal function. We observed vitamin $\mathrm{A}(81 \%)$ and active vitamin $\mathrm{B}_{12}$ (77\%) blood concentrations were above the normal reference ranges in the majority whilst vitamin $\mathrm{D}$ and zinc blood concentrations were below the normal reference ranges in $15 \%$ and $35 \%$ respectively. Blood concentrations of vitamin $\mathrm{E}$ $(67 \%)$, folate (92\%), copper (87\%) and selenium (85\%) were within the normal ranges for the majority of patients with only a small percentage of patients with low selenium (1\%) and copper $(7 \%)$ blood concentrations. Furthermore, except for vitamin $\mathrm{E}$, there were no significant differences in the mean blood concentrations of vitamin and trace elements across stages 3-5 of CKD. No symptoms of vitamin or trace element excesses/deficiencies were formally recorded in this study. There was no evidence of symptoms relating to low or high blood concentrations of vitamins or trace elements.

Vitamin A blood concentrations are known to be raised in those with impaired renal function and it has been shown that hypervitaminosis A is seen early in children with CKD [4]. High blood concentrations of vitamin A can lead to hypercalcaemia [2, 4], hyperlipidaemia and anaemia. Manickavasagar et al. [4] observed a $13 \%$ rise in serum retinol blood concentrations for every $10 \mathrm{~mL} / \mathrm{min} / 1.73 \mathrm{~m}^{2}$ decline in renal function. They also noted increased dietary vitamin A intake, in particular from supplementary feeds, was associated with hypervitaminosis. Whilst Rees and Shaw [2] noted that common UK practice is not to exceed $200 \%$ of the RNI from the diet and/or supplements, Manickavasagar et al. [4] based on their data, suggested that vitamin A intakes below the current RNI may be safe. In our study, of the children receiving feeds (and no multivitamins) $(n=15)$, feeds provided less than $100 \%$ of the RNI for vitamin A in 53\%; however, only one of these children had a normal vitamin A blood concentration with all others above the normal reference range.

Most children achieved normal vitamin E blood concentrations with the remaining blood concentrations above the normal reference range. Vitamin E concentrations significantly increased with worsening stage of CKD suggesting vitamin E blood concentrations increase as kidney function decreases. Furthermore, we previously showed a higher percentage of vitamin $\mathrm{E}$ blood concentrations above the normal reference range $(87 \%)$ in children on maintenance dialysis [5]. In the current study, the majority of children $(92 \%)$ had folate blood concentrations within the normal reference range with only a small number receiving a micronutrient supplement that contained folate $(n=10)$.

Active vitamin $\mathrm{B}_{12}$ concentrations were above the normal ranges in $77 \%$ of children regardless of whether they were receiving a multivitamin supplement or enteral tube feed containing vitamin $\mathrm{B}_{12}$. The majority of the patients received a non-renal-specific paediatric feed/formula to help meet their nutritional requirements which provided, in most cases, excessive amounts of vitamin $B_{12}$ compared with the RNI. Whilst modification of their enteral feed recipe to reduce the vitamin $\mathrm{B}_{12}$ content without impacting upon the feed overall nutritional quality may prove difficult, avoidance of additional sources of vitamin $B_{12}$, such as multivitamin supplements, is important. The K/DOQI report recommends the provision of dietary vitamin $\mathrm{B}_{12}$ intakes of at least $100 \%$ of the DRI with supplementation if vitamin $B_{12}$ intakes do not meet this [1]. In our study, one of the children who was feed dependent received less than the RNI for vitamin $B_{12}(90 \%)$. Despite this, they had a high active vitamin $\mathrm{B}_{12}$ blood concentration. As a result, where there are concerns over vitamin $B_{12}$ intake/status, it may be worthwhile testing vitamin $\mathrm{B}_{12}$ blood concentrations before supplementing with vitamin $\mathrm{B}_{12}$.

It is well recognized that vitamin D deficiency is common in children with CKD and contributes to CKD mineral and bone disorder and guidance on the vitamin D monitoring and supplementation in this population has recently been published [6]. In our study, vitamin D blood concentrations were within the desired range in $85 \%$ of children and cholecalciferol was appropriately commenced where indicated. Eighteen children were receiving a micronutrient supplement that contained vitamin D, of whom two had insufficient vitamin D blood concentrations ( $33 \mathrm{mmol} / \mathrm{L}$ and $49 \mathrm{mmol} / \mathrm{L}$ ) without which it is likely that their vitamin $\mathrm{D}$ concentrations would have been lower.

It has been reported that in $\mathrm{CKD}$, derangements in zinc homeostasis may occur due to several factors including disturbed renal excretion and altered protein metabolism [7]. Symptoms of zinc deficiency include impaired smell and taste [7], anorexia and impaired wound healing [1, 7]. Furthermore, zinc deficiency can negatively impact upon growth $[1,7]$. As highlighted by Yonova et al. [7], some of the symptoms of $\mathrm{CKD}$ resemble those of zinc deficiency.

The K/DOQI [8] has previously recommended monitoring zinc and copper intakes every 4 to 6 months and supplementing where intakes are low or in those where there is laboratory or clinical evidence of deficiency. Only seven children had low copper blood concentrations with the majority $(71 \%)$ of these blood concentrations only marginally below the reference range. Whilst it has been reported that a deficiency of copper can result in neutropenia and osteoporosis and can have a negative impact upon growth, an excess of zinc may aggravate marginal copper deficiency [1].

Although it is acknowledged that zinc blood concentrations can be low in CKD [7], few studies have investigated zinc blood concentrations in children with CKD, particularly in those with non-dialysis stages of CKD. The results of our study showed that zinc blood concentrations were below the normal reference range in 36 children, six of whom were receiving a micronutrient supplement which contained zinc. The latter provided 
approximately $50-60 \%$ of the RNI for zinc without which their zinc levels would likely have been even lower. There was no consistent evidence that providing the RNI for zinc in children receiving enteral tube feeds results in normal zinc blood concentrations. For example, eight children with low blood zinc concentrations were receiving enteral tube feeds (one also received a micronutrient supplement which contained zinc) which in 50\% of these provided $\geq 100 \%$ of the RNI for zinc. In comparison, the enteral tube feeds of $43 \%$ of children who had normal zinc blood concentrations provided only $62-$ $88 \%$ of the RNI for zinc.

With regard to selenium blood concentrations, the majority had normal concentrations $(85 \%)$ with only one child exhibiting low selenium blood concentrations indicating that routine monitoring of this trace element is not required in children with CKD who are conservatively managed. These findings are similar to those reported previously by us, where the majority of children on maintenance dialysis had normal selenium blood concentrations (89\%) [5], indicating that monitoring or supplementation of selenium is not required in children with CKD pre or whilst on maintenance dialysis.

The studies by Esmaeili and Rakhshanizadeh [9] and Esfahani et al. [10] reported no significant difference between the serum zinc and copper concentrations between healthy children and those with CKD receiving conservative management. Esmaeili and Rakhshanizadeh [9] also noted no significant difference between serum concentrations of selenium between healthy children and those with CKD receiving conservative management. Youssef et al. [11] reported that zinc and copper concentrations were significantly lower in children with CKD (stages 3 and 4) on conservative management, compared with healthy children. However, none of these studies provided information on the percentage of these trace elements within or outside the normal reference ranges. In addition, the number of children with conservatively management CKD in these studies was small and no information was provided on whether children were in receipt of oral nutritional supplements or enteral tube feeds.

There are several limitations to our study findings. These include the following: (1) Whilst we have discussed the RNI for several micronutrients in this study, it may be misleading to compare children with non-dialysis stages of CKD against these. We highlight here the relative lack of data and guidance on the micronutrient needs specific to this paediatric group; (2) Due to the retrospective nature of this study, data was not available for dietary intake at the time of the measurements. However, there are numerous known limitations with dietary intake assessments including errors in recall and misreporting of food portion sizes which can impact upon interpretation of micronutrient intakes; (3) As several micronutrients have agespecific ranges (such as copper and vitamins A and E), interpretation of results adds further difficulty. It is important to state that vitamin $B_{12}$ levels do not accurately reflect intake and if there any clinical concerns of $\mathrm{B}_{12}$ deficiency, levels should be measured. In this study, we have measured 'active vitamin $B_{12}$ (holo-transcobalamin)' concentrations as this is a more reliable marker of low vitamin $B_{12}$ status than that indicated by low level of serum vitamin $B_{12}$; (4) Data on adherence to prescribed supplements and over the counter micronutrients was not available; (5) Interpretation of data from our single-centre UK-based study needs to be factored against local childhood CKD population differences, their dietary intake, micronutrient supplements/supplementation practices and differences in enteral tube feeds/feed recipes.

\section{Conclusions}

The results of this largest study to date showed that the majority of children had vitamin A and active vitamin $\mathrm{B}_{12}$ blood concentrations above the normal reference ranges. Vitamin E alone showed significant difference in concentrations with worsening stage of CKD. We recommend targeted vitamin and trace element supplementation only. Monitoring of vitamin D (6 to 12 monthly) and zinc (3 to 6 monthly) blood concentrations is indicated due to higher proportions of patients with low levels in this group. Further research is required to expand this knowledge base including guidance on systematic monitoring and supplementation needs of vitamin and trace elements in infants and children with CKD.

Funding information The author (MDS) received financial support from the Department of Health via the National Institute for Health Research (NIHR) comprehensive Biomedical Research Centre and Clinical Research Facilities awards to Guy's and St Thomas' NHS Foundation Trust in partnership with King's College London and King's College Hospital NHS Foundation Trust. This article was made open access with the financial support of King's College London.

\section{Compliance with ethical standards}

The authors confirm that as this was a retrospective analysis evaluating results of clinical investigations, no consent from patients was indicated and ethical approval was not required.

Conflict of interest The authors declare that they have no conflict of interest.

Open Access This article is licensed under a Creative Commons Attribution 4.0 International License, which permits use, sharing, adaptation, distribution and reproduction in any medium or format, as long as you give appropriate credit to the original author(s) and the source, provide a link to the Creative Commons licence, and indicate if changes were made. The images or other third party material in this article are included in the article's Creative Commons licence, unless indicated otherwise in a credit line to the material. If material is not included in the article's Creative Commons licence and your intended use is not 
permitted by statutory regulation or exceeds the permitted use, you will need to obtain permission directly from the copyright holder. To view a copy of this licence, visit http://creativecommons.org/licenses/by/4.0/.

\section{References}

1. National Kidney Foundation Kidney Disease Outcomes Quality Initiative (K/DOQI) (2009) Clinical practice guideline for nutrition in children with CKD: 2008 update. Am J Kidney Dis 53(Suppl 2): S1-S124

2. Rees L, Shaw V (2007) Nutrition in children with CRF and on dialysis. Pediatr Nephrol 22:1689-1702

3. Jankowska M, Rutkowski B, Debska-Ślizień A (2017) Vitamins and microelement bioavailability in different stages of chronic kidney disease. Nutrients 9:282-289

4. Manickavasagar B, McArdle AJ, Yadav P, Shaw V, Dixon M, Blomhoff R, Connor GO, Rees L, Ledermann S, Van't Hoff W, Shroff R (2015) Hypervitaminosis A is prevalent in children with CKD and contributes to hypercalcemia. Pediatr Nephrol 30:317325

5. Joyce T, Court Brown F, Wallace D, Reid CJD, Sinha MD (2018) Trace element and vitamin concentrations in paediatric dialysis patients. Pediatr Nephrol 33:159-165
6. Shroff R, Wan M, Nagler EV, Bakkaloglu S, Cozzolino M, Bacchetta J, Edefonti A, Stefanidis CJ, Vande Walle J, Ariceta G, Klaus G, Haffner D, Schmitt CP, European Society for Paediatric Nephrology Chronic Kidney Disease Mineral and Bone Disorders and Dialysis Working Groups (2017) Clinical practice recommendations for treatment with active vitamin $\mathrm{D}$ analogues in children with chronic kidney disease stages 2-5 and on dialysis. Nephrol Dial Transplant 32:1114-1127

7. Yonova D, Vazelov E, Tzatchev K (2012) Zinc status in patients with chronic renal failure on conservative and peritoneal dialysis treatment. Hippokratia 16:356-359

8. National Kidney Foundation Kidney Disease Outcomes Quality Initiative (K/DOQI) (2000) Clinical practice guidelines for nutrition in CRF. Am J Kidney Dis 35(Suppl 2):S1-S40

9. Esmaeili M, Rakhshanizadeh F (2019) Serum trace elements in children with end-stage renal disease. J Ren Nutr 29:48-54

10. Esfahani ST, Hamidian MR, Madani A, Ataei N, Mohseni P, Roudbari M, Haddadi M (2006) Serum zinc and copper levels in children with chronic renal failure. Pediatr Nephrol 21:1153-1156

11. Youssef DM, Noseer AI, Abdallah AM, Aboelmag YE (2012) Evaluation of serum zinc and copper in children with chronic kidney disease. J Pediatr Biochem 2:57-60

Publisher's note Springer Nature remains neutral with regard to jurisdictional claims in published maps and institutional affiliations. 